\title{
CTLA-4 gene polymorphism is associated with predisposition to coeliac disease
} I Dijilali-Saiah, J Schmitz, E Harfouch-Hammoud, J-F Mougenot, J-F Bach,
S Caillat-Zucman genetically susceptible individuals. ${ }^{1}$ A significant part of the genetic component maps to the HLA class II region of the major histocompatibility complex (MHC). More than $90 \%$ of patients with coeliac disease express a DQ $\alpha \beta$ heterodimer encoded by the DQB $1{ }^{\star} 02$ (DQ2) and $\mathrm{DQA} 1{ }^{\star} 0501$ alleles in the cis position in DR3 patients, or in the trans position in DR7/11 heterozygous patients..$^{2-4}$ However, some individuals develop a typical disease in the absence of known predisposing alleles. ${ }^{5-7}$

Previous family studies have suggested that other non-HLA loci might be stronger determinants of inheritance of coeliac disease than the HLA locus itself. ${ }^{8} 9$ A genome wide screening approach using polymorphic microsatellite markers in affected sibpairs from western counties of Ireland has recently proposed several candidate regions that might contribute to coeliac disease. ${ }^{10}$ However, only one of the newly mapped intervals has been replicated in a linkage analysis study of 28 coeliac disease families, ${ }^{11}$ confirming that several independent studies are required for confirmation of linkage results in complex multigenic diseases. This is further complicated by heterogeneities in different populations and/or ethnic groups.

Another approach involves analysis of candidate genes that are directly related to autoimmune disorders, using the case control association method. CTLA-4 on chromosome 2q33 is a likely candidate gene for autoimmune diseases because of its role in controlling the T cell proliferative response. The CTLA-4 gene encodes a $\mathrm{T}$ lymphocyte surface molecule whose binding to the B7 molecule on antigen presenting cells delivers a negative signal to the $\mathrm{T}$ cell and can mediate its apoptosis. ${ }^{12} 13$ CTLA-4 deficient mice develop a lymphoproliferative disease with multiorgan lymphocytic infiltration and tissue destruction. ${ }^{14}{ }^{15}$ Association of insulin dependent diabetets mellitus (IDDM) and Graves' disease with a point mutation in exon 1 of CTLA-4 (position 49 A/G) leading to a Thr/Ala substitution in the leader peptide has recently been described in several different populations by combined association and linkage studies. ${ }^{16-20}$

The functional importance of the CTLA-4 molecule has prompted us to examine its contribution to predisposition to coeliac disease in unrelated individuals.

Coeliac disease is a gluten sensitive enteropathy characterised by small bowel mucosal atrophy. A T cell mediated immune response to some immunodominant wheat gliadin peptides may play a crucial role in the disease. Ingestion of gluten containing cereals probably induces immunologically mediated intestinal injury in

\section{Patients and methods}

One hundred and one French Caucasian patients with coeliac disease (54 females, 47 males) were recruited from the Departments of Pediatrics, Hôpital Necker-Enfants Malades, 
Table 1 Polymorphism at CTLA-4 exon 1 position 49 in patients with coeliac disease and controls

\begin{tabular}{llll}
\hline $\begin{array}{l}\text { Nucleotide at position } 49 \\
\text { (codon at position 17) }\end{array}$ & $\begin{array}{l}\text { Coeliac disease } \\
(n=101)\end{array}$ & $\begin{array}{l}\text { Controls } \\
(n=130)\end{array}$ & Odds ratio $(95 \%$ CI) \\
\hline $\begin{array}{l}\text { Phenotype frequencies } \\
\text { A positive (Thr) }\end{array}$ & $97(96.0)$ & $109(83.8)$ & $4.67(1.54-14.09)^{\star}$ \\
$\quad$ G positive (Ala) & $32(31.7)$ & $68(52.3)$ & $0.42(0.24-0.72)^{\star}$ \\
Genotype frequenciest & $69(68.3)$ & $62(47.7)$ & $2.36(1.37-4.06) \ddagger$ \\
AA (Thr/Thr) & $28(27.7)$ & $47(36.2)$ & $0.21(0.07-0.64) \ddagger$ \\
AG (Thr/Ala) & $4(4.0)$ & $21(16.2)$ & \\
GG (Ala/Ala) & $166(82.2)$ & $171(65.8)$ & \\
Allele frequencies $\$$ & $36(17.8)$ & $89(34.2)$ & \\
A (Thr) & & & \\
G (Ala) & &
\end{tabular}

Results are expressed as number (\%).

${ }^{\star} \mathrm{p}$ values of odds ratios defined by Fisher's exact test (A phenotype), or $\chi^{2}$ test $(1 \mathrm{DF})$ using a $2 \times 2$ contingency table ( $G$ phenotype); $\mathrm{p}=0.0027$ for both.

$+\chi^{2}$ test of heterogeneity ( $2 \mathrm{DF}$ ) using a $3 \times 2$ contingency table; $\mathrm{p}=0.0013$.

$\neq \mathrm{p}$ values of odds ratio for GG and AA genotypes; $\mathrm{p}=0.0027$ for both.

$\S \chi^{2}$ test of heterogeneity $(1 \mathrm{DF})$ using a $2 \times 2$ contingency table; $\mathrm{p}<0.0001$.

Hôpital Robert Debré, and Hôpital Trousseau, Paris, and have been described in detail elsewhere. ${ }^{72}$ All were diagnosed during childhood from 1981 to 1995 and fulfilled ESPGAN criteria. The control group consisted of 130 French Caucasian blood donor volunteers.

HLA class II typing was performed using sequence specific oligotyping after genomic DNA amplification of the DRB1, DQB1, and DQA1 loci by the polymerase chain reaction (PCR). ${ }^{22}$

The CTLA-4 exon 1 position 49 A/G polymorphism was typed using standard PCR allele specific dot blot hybridisation as previously described, ${ }^{17}$ with PCR primers (forward 5'-GCTCTACTTCCTGAAGACCT-3' and reverse 5'-AACCCAGGTAGGAGAAACAC3'; 35 cycles of 30 seconds at $94^{\circ} \mathrm{C}$ for denaturing, 30 seconds at $50^{\circ} \mathrm{C}$ for annealing, and 60 seconds at $72^{\circ} \mathrm{C}$ for extension) and detection oligonucleotides (5'AACCTGGCTGCCAGGACC-3' and 5'AACCTGGCTACCAGGACC-3'). The presence of the $G$ allele of CTLA-4 position 49 polymorphism was confirmed by digestion of the PCR product with the restriction endonuclease BbvI and visualisation of the fragments on $2.5 \%$ agarose gels stained with ethidium bromide.

Allele and phenotype frequencies were determined for patient and control groups. Odds ratios (OR) were calculated according to Woolf's formula, and the $\mathrm{p}$ value was defined

Table 2 CTLA-4 genotypes in HLA class II matched patients with coeliac disease and controls

\begin{tabular}{llll}
\hline & \multicolumn{2}{l}{ HLA genotype } & \\
\cline { 2 - 4 } & $A A$ & $A G$ & $G G$ \\
\hline $\begin{array}{l}H L A D R 3 \text { positive } \\
\text { Coeliac disease }\end{array}$ & $46(65.7)$ & $21(30.0)$ & $3(4.3)$ \\
Controls & $8(33.4)$ & $11(45.8)$ & $5(20.8)$ \\
$H L A D R 3$ negativet & $23(74.2)$ & $7(22.6)$ & $1(3.2)$ \\
$\begin{array}{l}\text { Coeliac disease } \\
\text { Controls }\end{array}$ & $54(51.0)$ & $36(34.0)$ & $16(15.0)$ \\
$\begin{array}{l}\text { Coeliac disease } \\
\text { Controls }\end{array}$ & $64(68.0)$ & $26(27.7)$ & $4(4.3)$ \\
$H L A D Q A 1^{\star} 0501 / D Q B 1 * 02$ positives & $19(43.2)$ & $17(38.6)$ & $8(18.2)$ \\
Coeliac disease & $59(70.2)$ & $21(25.0)$ & $4(4.8)$ \\
Controls & $9(34.6)$ & $12(46.2)$ & $5(19.2)$ \\
\hline
\end{tabular}

Results are expressed as number (\%).

$\chi^{2}$ test of heterogeneity ( $\left.2 \mathrm{DF}\right)$ using a $3 \times 2$ contingency table.

${ }^{\star} \mathrm{p}=0.005 ; \mathrm{tp}=0.04 ; \neq \mathrm{p}=0.004 ; \mathrm{d} \mathrm{p}=0.002$. by $\chi^{2}$ analysis using a $2 \times 2$ or $2 \times 3$ contingency table, or Fisher's exact test where appropriate. A value of $p<0.05$ was considered significant.

\section{Results}

The frequency of $G$ allele positive individuals was significantly increased in patients with coeliac disease relative to controls $(96 \%$ and $83.8 \%$ respectively; OR $4.67,95 \%$ confidence interval (CI) 1.54 to $14.09, \mathrm{p}=0.002$; table 1 ). The A allele frequency was $82.2 \%$ in patients with coeliac disease compared with $65.8 \%$ in controls $(p<0.0001)$. This difference reflected a significant increased frequency of the $\mathrm{A} / \mathrm{A}$ genotype in patients $(68.3 \%$ versus $47.7 \%$ in controls; OR 2.36, CI 1.37 to $4.06, \mathrm{p}=0.002$ ). Conversely, the $\mathrm{G} / \mathrm{G}$ genotype was observed in only $4 \%$ of patients with coeliac disease compared with $16.2 \%$ of controls (OR $0.21, \mathrm{CI}$ 0.07 to $0.64, \mathrm{p}=0.002$ ).

To investigate a possible interaction between the CTLA-4 and HLA genes, stratification of the patients was done according to their DR-DQ phenotype (table 2). The distribution of $A$ and $G$ alleles was first compared in $\mathrm{DRB} 1{ }^{\star} 03-\mathrm{DQB} 1{ }^{\star} 02-\mathrm{DQA} 1{ }^{\star} 0501$ positive or negative patients and matched controls. The increased frequency of the A/A genotype and the decreased frequency of the G/G genotype were still observed in all coeliac disease patient subgroups relative to controls, whatever the HLA phenotype $\left(2 \times 3 \chi^{2}\right.$ contingency table analysis, $p=0.005$ and $p=0.04$ respectively). In the same manner, patients and controls stratified for the presence of the HLA-DQB $1{ }^{\star} 02$ allele or for the presence of the cis or trans encoded DQA $1{ }^{\star} 0501 / \mathrm{DQB} 1{ }^{\star} 02$ heterodimer were compared. The vast majority of patients with coeliac disease expressed the A allele of the CTLA-4 position 49 polymorphism in both groups $(95.7 \%$ and $95.2 \%$ respectively, versus $81.6 \%$ and $80.8 \%$ in controls; $2 \times 3 \chi^{2}$ contingency table analysis, $\mathrm{p}<0.002)$. In particular, the four patients with coeliac disease showing the unfrequent $G / G$ genotype all expressed the predisposing $\mathrm{DQA} 1{ }^{\star} 0501 / \mathrm{DQB} 1{ }^{\star} 02$ heterodimer, encoded either in cis (one DR3/4 patient), in trans (one DR7/11 patient), or in both positions (two DR3/7 patients).

\section{Discussion}

Although the HLA component of coeliac disease susceptibility is well characterised and relatively simple, little is known about the role of genes other than HLA. One or more genes at HLA unlinked loci also predispose to coeliac disease and are probably stronger determinants of disease susceptibility than HLA, as indirectly shown by the high disease concordance rate in monozygotic twins $(71 \%)$ compared with only $30 \%$ in HLA identical siblings. ${ }^{23}$ The non-secretor state, using red cell Lewis (Le) blood group phenotype to infer secretor status, has been reported to be significantly associated with coeliac disease, ${ }^{24}$ suggesting that genes on chromosome 19 may directly or indirectly participate in conferring disease susceptibility. A recent genome wide study, ${ }^{10}$ has proposed a number of candidate regions on chromosomes $6 \mathrm{p} 23$ (distinct from HLA), 6p12, 3q27, 
5q33.3, 7q31.3, 11p11, 15q26, 19p13.3, $19 \mathrm{q} 13.1,19 \mathrm{q} 13.4$, and 22 cen for the location of a non-HLA linked susceptibility gene. However, in another linkage study, ${ }^{11}$ there was no significant evidence for linkage of coeliac disease to these markers, except for D15S642 on chromosome $15 \mathrm{q} 26$.

Our results show an association of the $\mathrm{A}$ allele of CTLA-4 position 49 polymorphism with predisposition to coeliac disease. The frequency of this allele was not more increased in patients expressing the classic predisposing HLA alleles or allelic combinations, which suggests that the effects of the HLA and CTLA-4 loci are independent. Because of the well known clinical heterogeneity in coeliac disease, in particular according to the age at disease onset and the autoantibody status of the patients, it might be interesting to try to relate genotype to disease presentation. In the present study however, all the patients were diagnosed during childhood. Furthermore, most of them were diagnosed before antiendomysium antibodies were routinely used as a screening test, so that it was not possible to analyse the relation between this parameter and the genetic marker studied.

Whether CTLA- 4 contributes to coeliac disease susceptibility by itself, or is a marker for another locus in linkage disequilibrium with CTLA-4, is unclear. Furthermore, the aetiological mutations on the CTLA-4 gene may not have been found. The dimorphism at position 49 of exon 1, leading to Thr/Ala substitution at codon 17 of the peptide leader, is unlikely to affect the function of the molecule. Moreover, the association of the $G$ allele of CTLA-4 position 49 polymorphism with both IDDM and Graves' disease, ${ }^{16-20}$ as opposed to the association of the A allele with coeliac disease, provides indirect evidence that the $A / G$ polymorphism is not the aetiological mutation. As the product of the CTLA-4 gene is involved in the negative regulation of $\mathrm{T}$ cell activation, it would be surprising if it conferred susceptibility to different autoimmune disorders by opposite mechanisms. A polymorphic microsatellite (AT)n repeat in the 3 ' untranslated region of the CTLA-4 gene has been shown to be in strong linkage disequilibrium with the exon 1 dimorphism located $5.3 \mathrm{~kb}$ upstream. ${ }^{17}{ }^{19}$ This microsatellite polymorphism could affect RNA stability, ${ }^{16}$ and explain the CTLA-4 contribution to disease predisposition.

Alternatively, other genes in close proximity to CTLA-4 on chromosome $2 \mathrm{q}-33$ might be involved in predisposition to coeliac disease and other autoimmune disorders. Although chromosome $2 \mathrm{q}-33$ has not been identified among regions that contribute to coeliac disease in linkage studies, ${ }^{10}{ }^{11}$ it contains several candidate genes. The CD28 gene, which is within $25-150 \mathrm{~kb}$ of CTLA- $4,{ }^{12}$ encodes a major molecule providing a positive costimulatory signal for $\mathrm{T}$ cell activation through interaction with $\mathrm{B} 7$ on antigen presenting cells, and might well play an important role in the development of autoimmunity. A cluster of interleukin 1 (IL-1) genes (IL-1A, IL-1B, IL-1 receptors IL-1R1 and IL-1R2, and receptor antagonist IL-1RA) also maps to the 2q12-22 region. Detailed physical and genetic mapping of the region surrounding CTLA-4, as well as characterisation of multiple polymorphisms by DNA sequencing, will be required for the identification of the aetiological mutation conferring suceptibility to coeliac disease and other autoimmune disorders.

I Djilali-Saiah was supported by the Fondation pour la Recherche Médicale.

1 Trier JS: Coeliac Sprue. N Engl f Med 1991;325:1709-19.

2 Mazzilli MC, Ferrante P, Mariani P, et al. A study of Italian pediatric coeliac disease patients confirms that the primary
HLA association is to the DQ $\left(\alpha 1^{\star} 0501, \beta \star^{\star} 0201\right)$ heterodimer. Hum Immunol 1992;33:133-9.

3 Tighe MR, Hall MA, Barbado M, et al. HLA class II alleles associated with coeliac disease susceptibility in a southern European population. Tissue Antigens 1992;40:90-7.

4 Sollid LM, Markussen G, Ek J, et al. Evidence for a primary association of coeliac disease to a particular HLA-DQ $\alpha / \beta$ heterodimer. F Exp Med 1989;169:345-50.

5 Heitzel PAS, Benneti GD, Sheldon AB, et al. Genetic markers in Australian Caucasian subjects with coeliac disease. Tissue Antigens 1987;30:18-22.

6 Spurkland A, Sollid LM, Polanco I, et al. HLA-DR and -DQ genotype of coeliac disease patients serologically typed to

7 Djilali-Saiah I, Caillat-Zucman S, Schmitz J, et al. Polymorphism of antigen processing (TAP, LMP) and HLA class II genes in coeliac disease. Hum Immunol 1994;40:8-16.

8 Greenberg DA, Rotter JI. Two locus models for gluten sensitive enteropathy: population genetic considerations. Am $\mathcal{F}$ Med Genet 1981;8:205-14.

9 Risch N. Assessing the role of HLA-linked and unlinked determinants of disease. Am $\mathcal{F}$ Med Genet 1987;40:1-14.

10 Zhong F, McCombs CC, Olson JM, et al. An autosomal screen for genes that predispose to coeliac disease in the western counties of Ireland. Nat Genet 1996;14:329-33.

11 Houlston RS, Tomlinson IP, Ford D, et al. Linkage analysis of candidate regions for coeliac disease genes. Hum Mol Genet 1997;6:1335-9.

12 Harper K, Balzano C, Rouvier E, et al. CTLA-4 and CD28 activated lymphocyte molecules are closely related in both mouse and human as to sequence, message expression,
gene structure, and chromosomal location. $\mathcal{F}$ Immunol 1991;147:1037-44.

13 Walunas TL, Lenschow DJ, Bakker CY, et al. CTLA-4 can function as a negative regulator of $\mathrm{T}$ cell activation. Immunity 1994;1:405-13.

14 Tivol EA, Borriello F, Schweitzer AN, et al. Loss of CTLA-4 leads to massive lymphoproliferation and fatal multiorgan leads to massive lymphoproliferation and fatal multiorgan
tissue destruction. Revealing a critical negative regulatory role of CTLA-4. Immunity 1995;3:541-7.

15 Waterhouse P, Penninger JM, Timms E, et al. Lymphoproliferative disorders with early lethality in mice deficient in CTLA-4. Science 1995;270:985-8.

16 Yanagawa T, Hidaka Y, Guimaraes V, et al. CTLA-4 gene polymorphism associated with Graves' disease in Caucasian population. F Clin Endocrinol Metab 1995;80:41-5.

17 Nistico L, Buzzetti R, Pritchard LE, et al. The CTLA-4 gene region of chromosome 2q33 is linked to, and associated with, type 1 diabetes. Hum Mol Genet 1996;5:1075-80.

18 Donner H, Rau H, Walfich PG, et al. CTLA-4 alanine confers genetic susceptibility to Graves' disease and to type 1 diabetes mellitus. F Clin Endocrinol Metab 1997;82:143-6.

19 Marron MP, Raffel LJ, Garchon HJ, et al. Insulin-dependent diabetes mellitus (IDDM) is associated with CTLA-4 diabetes mellitus (IDDM) is associated with CTLA-4
polymorphisms in multiple ethnic groups. Hum Mol Genet polymorphisms in

20 Djilali-Saiah I, Larger E, Harfouch-Hammoud E, et al. No Djilali-Saiah I, Larger E, Harfouch-Hammoud E, et al. No
major role for the CTLA-4 gene in the association of major role for the CTLA-4 gene in the association of
autoimmune thyroid disease to IDDM. Diabetes 1998;47: autoimm 125 .

21 Meddeb-Garnaoui A, Zeliszewski D, Mougenot JF, et al. Reevaluation of the relative risk for susceptibility to coeliac disease of HLA-DRB1, DQB1, DPB1, and TAP2 alleles in a French population. Hum Immunol 1995;43:190-4.

22 Caillat-Zucman S, Garchon HJ, Timsit J, et al. Agedependent HLA genetic heterogeneity of type 1 insulin dependent diabetes mellitus. F Clin Invest 1992,90:224250 .

23 Walker-Smith JA. Discordance for childhood coeliac disease in monozygote twins. Gut 1973;14:374-5.

24 Dickey W, Wylie JD, Collins JS, et al. Lewis phenotype, secretor status, and coeliac disease. Gut 1994;35:769-70. 